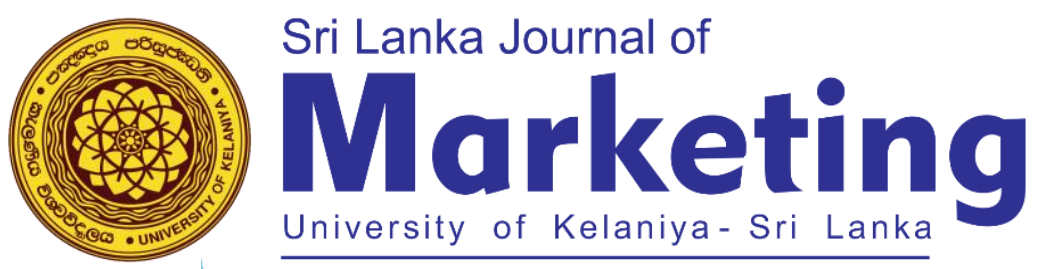

\title{
Impact of Brand Citizenship Factors towards Customer Perception: A Conceptual Review on Non-Banking Financial Services Sector of Sri Lanka
}

\author{
G. A. Sanka Jayampathi \\ Doctoral Student, University of Kelaniya, Sri Lanka \\ sankajlinda@gmail.com \\ Weerasiri R. A. S. \\ Senior Lecturer, University of Kelaniya, Sri Lanka \\ sudath@kln.ac.lk
}

\begin{abstract}
The Main objective of the concept paper is to review of brand citizenship factors relates to customer perception. A special attention is paid to matters pertaining to the non-banking financial services sector in Sri Lanka. In order for the leasing industry to survive in a competitive market, all firms need to understand customers who are more inclined to reconsider their relationship with other paroral players and competitors. Marketing experts focus on investigating the factors that create and increase consumer value in this new light. Organizations sustain their competitive advantage though differentiation strategy and cost leadership. Employee's brand behavior would be the best practices for brand differentiation. Inline within, scholars appreciate the concept of Brand Citizenship Behavior (BCB) as one of the theoretical contents that addressee's customer perception. Most organizations are to maintain balance standpoint in brand citizenship management which highlights both external and internal brand management Sri Lanka is also a noted context whereas financial services apply such motivational strategies to train and retain brand committed salesforce. But organizations in the financial leasing sector still faces intensive issues for the customer perception due to on revelry competition among the parallel players and the competitors. This paper reviews how theoretical and empirical contributions address customer perception whilst special attention is made on non-banking financial services sector in Sri Lanka. Alongside, authors used a deductive approach so doing paper associated academic works and industry related publications to support arguments and discussions. A summarized discussion was made whilst key insights are concluded with future research suggestions.
\end{abstract}

Keywords: Brand Citizenship Behavior, Customer Perception, Non-Banking Financial Services Sector, Sri Lanka 


\section{INTRODUCTION}

Sri Lanka has been identified widely in the South Asian region as an economy which is heavily driven based on the services sector. Furthermore, the service sector of Sri Lanka has been recognized as an imperative contributor toward the national GDP, which also generates employment for more than 160,000 direct employees (Central Bank, 2019).

\section{Figure 1: Non-Banking Financial services sector Sri Lanka}

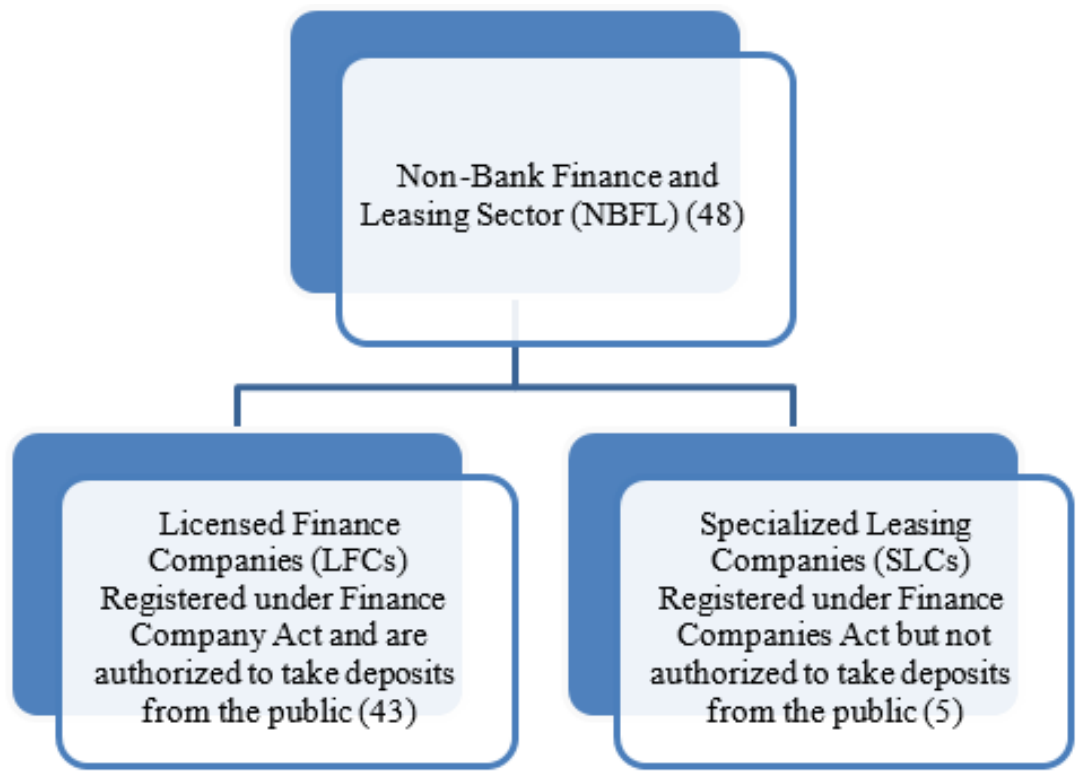

Source: Central Bank, 2019

As at end of 2018, NBFS sector comprised 43 licensed financial companies and 5 specialized leasing companies. Furthermore, NBFS has been granted high recognition due to the core role it plays along with banks for the development of the nation and the contribution toward the GDP od the nation. Moreover, NBFSs support in boosting and enhancing economic performance of a nation that cannot be accomplished successfully solely through banks. Furthermore, NBFSs can reach niche and differentiated market segments of an economy, where commercial sectors and banking sectors have drawbacks (Edirisinghe, 2018). Furthermore, NBFSs have a key role in the differentiated services sector as they offer tailor-made offerings that suit differentiated expectations and needs of customer segments. This indicates that NBFS sector is a critical contributor for the economic development of a country, whereas employee performance is a critical factor for its long-term survival, which drives effective customer centricity and customer orientation. Moreover, the significance of the leasing, money lending, estate and housing finance operations, factoring services and merchant banking are unparalleled and significant services offered through NBFSs (Ahamed \& Chowdhury, 2007; Debnath 2004; Nasreen \& Jahan, 2007; Central Bank Report, 2019). Thus, NBFSs in Sri Lanka context too are having significance in this regard and thereby the 
It can be seen different universal and locally established brands, such as Assetline, LOLC, LB Finance, Orient Finance and etc (Central Bank Report, 2019). All these organizations are contending in a similar mark and the NBFS faces intense rivalry and competition (Nuwaz, 2015). Achieving a new client is not an easy task, front line staff makes a key role in this with competition and trending customer behavior (Nirmali, Khathibi, \& Azam, 2018). Unlike a product, the quality of service depend on who provides them therefore it is important to have engaged, well-prepared and experienced employees to direct and engage with them (Kotler et al, 2013). The brand citizenship behavior factors can be used for staff motivation in nonbank financial leasing sector in Sri Lanka (Jayampathi \& Dissanayake 2018).

\section{MOTIVATION OF THE STUDY}

Brand-consistent behavior commonly discussed based on two major streams, namely (i) in-role brand behavior and, (ii) extra-role brand behavior. For instance, Kimpakorn and Tocquer (2009), King and Grace (2008) and Punjaisri and Wilson (2007) highlighted brand-consistent behavior as more toward in-role brand behavior while Morhart, Herzog and Tomczak (2008) and Burmann et al. (2008) stated that brand-consistent behavior is best described as extra-role brand behavior. However, there is no consistent terminology used for both concepts of brand-consistent behavior. Another major issue concerned with such concept (in-role and extra role brand behavior) is regarding un-dimensional versus multidimensional of employees' brand-consistent behavior. Therefore, the study at hand will examine whether such employees' brand-consistent behavior is un-dimensional or best explained by multidimensional concept. In essence, in-role brand behavior is related to an ability of employees to deliver the brand promise. According to Morhart et al. (2008), in-role brand behavior is meeting prescribed brand roles while Burmann et al. (2008) termed this as brand compliance. In-role brand behavior would be easily fulfilled by most organization. Extra-role brand behavior refers to employees' willingness to take extra miles on behalf of the organization's brand. This includes job or task or behavior that goes beyond formal prescribed brand roles such as positive word of mouth, participation, helping behavior, sportsmanship, brand enthusiasm and other employees' extra brand effort (Burmann et al. 2008; Morhart et al. 2008). Based on the assumption that organization sustained their brand competitive advantage through differentiation strategy, thus, extra-role brand behavior would be the best practice for brand differentiation. This is because, to engage employees with extra-role brand behavior that goes beyond their formal brand role is not easily found in every organization/brand. Moreover, Burmann et al. (2008) suggested that extra-role brand behavior is more superior to in-role brand behavior in stimulating favorable brand identity. As such, extra-role brand behavior will be examined in this study which is conceptualized as brand citizenship behavior

Brand citizenship behavior (BCB) is a relatively new concept that explains how employees could improve their brand delivery performance by aligning their attitude and behavior to the organization's brand (Burmann \& Zeplin, 2005). In essence, brand citizenship behavior refers to the employees' 
voluntary basis to show case a number of generic employees' behaviors that lead to the formation of enhanced brand identity (Burmann \& Zeplin 2005;Nirmali,et.al.2018). BCB has been studied in many industries. Industry practices of Sri Lankan NBFI sector highlight intensive efforts being used to address customer perception issues.

\section{METHODOLOGY}

This research paper has been developed with the research design being considered as a concept paper in which the deductive research approach has been followed (Trochim, 2006). As per Trochim (2006), it has been evident that there are two wide methods that are used for the purpose of reasoning and applying the inductive or deductive research approach for a research study. Alongside, deductive approach is applied by reviewing empirical arguments derived from past research on how brand citizenship behavior matters in sales force motivation; whilst specific concern is focused on special leasing companies of Sri Lanka. Moreover, information gathered through experiences, experiments and observations are considered as inductive techniques whereas information gathered through laws, principles, models, rules, theoretical perspectives are considered as deductive techniques (Trochim, 2006). Deductive studies associate models, theories and laws to build arguments for a research direction (Creswell and Clark, 2007). Accordingly, this paper follows the main research tool as a literature review so as to test and explain empirical and theoretical contents. In line within; journal articles, secondary statistics of Sri Lankan financial sector and book chapters have been associated to develop review and discussion. Finally, paper presents literature-based explanations followed by a discussion whilst future research propositions are also concluded.

\section{LITERATURE REVIEW}

\subsection{Brand Citizenship Behavior}

Brand citizenship behavior (BCB) is a relatively new concept that explains how employees could improve their brand delivery performance by aligning their attitude and behavior to the organization's brand. In essence, brand citizenship behavior refers to the employees' voluntary basis to show case and radiate a number of generic employees' behaviors that contribute toward enhancing the brand identity (Burmann \& Zeplin, 2005). Additionally, brand citizenship behavior results customer satisfaction (Verma \& Dhar, 2015). BCB has been originated from organizational citizenship behavior that acknowledged the internal micro-level performance (i.e. employee's brand performance) to external target groups rather than macro-level performance (i.e. job and organizational performance) alone. According to Burmann et al. (2008), BCB is built up of seven constructs that are believed to represent the brand-related behavior of employees to enhance the organization's brand success and later sustain the organization's competitive advantages. The constructs are as follows: 
- Helping Behavior. Helping behavior is associated with positive attitude, friendliness, helpfulness, and empathy toward internal and external customers, taking responsibility for tasks outside of their town area if necessary such as following up on complaints.

- Sportsmanship. Sportsmanship is associated with no complaining, even if engagement for the brand cause inconvenience; willingness to engage for the brand even at some opportunity cost.

- Brand Endorsement. Brand endorsement refers to employee's recommendation of the brand to others even in non-job-related situations for example, to friends; passing on the brand identity to newcomers in the organization

- Brand Enthusiasm. Brand enthusiasm refers to employee's ability to show extra initiative while engaging in brand-related behavior.

- Brand Consideration. Brand consideration refers to employee's adherence to brand-related behavior guidelines and reflection of brand impact before communicating or taking action in any situation. .

- Self-development. Self-development refers to employee's willingness to continuously enhance brand-related skills.

- Brand-advancement. Brand advancement refers to employee's contribution to the adaptation of the brand identity concept to change market needs or new organizational competencies, such as through passing on customer feedback or generating innovative ideas.

In denotes BCB connects to different contents of how staff adheres to brand promise. In brief, King \& Grace (2008) said brand knowledge affects employees' brand role referring how they are willing to engage in brand supportive behavior. But Kimpakorn and Tocquer (2009) failed to find much support on brand knowledge relates on brand commitment and other behavioral aspects required for brand support. Furthermore, according to assumptions of Burmann et. al. (2008) brand knowledge works as a mediating variable, but not as a key determinant of employees BCB. Evidently, employees especially in the service industry implicitly project the brand identity to consumers (Kimpakorn \& Tocquer, 2010). Factors related to self-concept of employees found a direct impact on BCB (Helm, Renk, and Mishra, 2016). Thus, it denotes concept of BCB finds interesting arguments on its influence whilst different industries attribute speckled evidences on its effectiveness.

Moreover, brand-consistent behavior is commonly being discussed based on two major streams namely in-role brand behavior and extra-role brand behavior. For instance, Kimpakorn and Tocquer (2009), King and Grace (2008) and Punjaisri and Wilson (2007) highlighted brand-consistent behavior as more 
toward in-role brand behavior while Morhart, Herzog and Tomczak (2008) and Burmann et al. (2008) stated that brand-consistent behavior is best described as extra-role brand behavior. However, there is no consistent terminology used for both concepts of brand-consistent behavior. Another major issue concerned with such concept (in-role and extra role brand behavior) is regarding uni-dimensional versus multidimensional situations of employees' brand-consistent behavior. Therefore, the study at hand will examine whether such employees' brand-consistent behavior is uni-dimensional or best explained by multidimensional concepts. In essence, in-role brand behavior is related to an ability of employees to deliver the brand promise. According to Morhart et al. (2008), in-role brand behavior is meeting prescribed brand roles while Burmann et al. (2008) termed this as brand compliance. In-role brand behavior would be easily fulfilled by most organizations. Extra-role brand behavior refers to employees' willingness to take extra miles on behalf of the organization's brand. This includes job or task or behavior that goes beyond formally prescribed brand roles and job descriptions such as positive word of mouth, active participation, helping behavior, sportsmanship, brand enthusiasm and other employees' extra brand effort (Burmann et al. 2008; Morhart et al. 2008). Based on the assumption that organizations sustained their brand competitive advantage through differentiation strategy, thus, extrarole brand behavior would be the best practice for brand differentiation. This is because, to engage employees with extra-role brand behavior that goes beyond their formal brand role is not easily found in every organization/brand. Moreover, Burmann et al. (2008) suggested that extra-role brand behavior is more superior to in-role brand behavior in stimulating favorable brand identity. As such, extra-role brand behavior will be examined in this study which is conceptualized as brand citizenship behavior.

In general, the constructs cover employees' consideration towards the brand that goes beyond their formally prescribed job description mainly to deliver the brand promise in an appropriate manner. Thus, based on the comprehensiveness of the brand behavior construct proposed by Burmann \& Zeplin (2005), brand citizenship behavior will be adapted because it provides a more holistic view of brand performance in the context of employees as opposed to other's works. However, the research findings of Burmann et al. (2008) revealed that four out of seven constructs (namely helping behavior, brand endorsement, brand sportsmanship and brand enthusiasm) directly expose to customers. As such, there is the need to test the construct with the new data set mainly to increase the superiority of the construct.

Punjaisri, Evanschitzky and Wilson (2009) mention that the objective of following internal branding efforts is to make sure that employees of organization would transform the brand messages into brand reality that is perceived by customers and other stakeholders" (p.60). Therefore, a brand is essentially presented by an organization's employees, who transfer internal characteristics of the brand to external environments (Burmann \& Zeplin, 2005). Brand citizen behavior (BCB) is one of the most important factors for internal branding, which is a determinant of a strong brand (Burmann, Zeplin\& Riley, 2009). 
BCB refers to employees' voluntary brand-oriented behavior, which goes above and beyond their formal role requirements and brings the brand alive and to life (Burmann \& Zeplin, 2005.

Many business organizations strictly focus on brand management from the perception of customers which is directed toward understanding customer behavior towards the brand. According to Keller (1993) there was one source of most cited literature in brand equity that led to building 'CustomerBased Brand Equity' (CBBE) theory which is concerned on how customers' behavior contributed to a long term brand survival. At present, with challenging business environments, in order to sustain the brand's competitive advantage, companies should maintain balance standpoint in brand management which highlights both external and internal brand management. This occurs because; the workers of the company that represent the brand have an opportunity to develop the image of the brand and the status as well as performance of the brand through the behavior and the attitude of them, mostly when they are delivering the service (Burmann, et. al. 2005). Hence, the management should recognize and inspire employees' work that could improve the complete brand routine.

As to 'de Chernatony and Cottam' (2009), workers are known as the brand delivery. Accordingly, in order to deliver the promise of the brand, employees should equally improve their behavior and attitude according to the value of the brand (Ind. 2001) by 'living the brand'. Knowledge of how employees could improve the performance of the brand somewhat limited (Punjaisri \& Wilson, 2007) in Sri Lankan perspective. Thus, this occurs because many studies have been engaged to understand the customer's behavior better that led to improve 'customer-based brand equity' (e.g. Keller, 1993).

The studies focusing mainly on how BCB factors influence on employee motivation, and the current attempts to study about understanding on how obstinately focus on the urgencies of the employees to repeatedly keep up the equality between the behavior and the attitude towards the value of the brand by 'living the brand'. Presently, except Burmann and Zeplin (2005) and Burmann, Zeplin and Riley (2008), there are no disagreements of what is expected by the employees of the organization's 'brand behavior that 'live the brand'. In this regard, Urmann and Zeplin (2005) have recognized seven leading employers' behavioral patterns that proportionate with living the brand concept that is collectively referred to as 'brand citizenship behavior' (BCB).

Moreover, as per Burmann and Zeplin (2005) it has been discovered that there are seven key attributes that lead the employee behavior that resonates with living the brand concept, which is termed as "brand citizenship behavior (BCB). These seven key attributes include (helping behavior of employees, selfdevelopment and self-attainment of employees, enthusiasm toward the brand, and consideration of the brand, sportsmanship that is radiated, advancement of brand and endorsement of brand. However, as per Burmann et al. (2008), it has been found that BCB is derived based on three main factors that are enthusiasm toward brand, helping behavior of employees and development of brand. Therefore, the 
researchers have recommended that measuring activity of BCB should be carried out in such a way as to test to derive the advantages

The concept is still open to be researched. It is still recommended that without sufficient brand-related knowledge, workers of the company are not able to understand what is needed for the delivery of the brand promise and to live up the brand. Therefore, similarly, it is significant to understand how the workers' education about the brand affects their behavior, especially when $\mathrm{BCB}$ is considered. Literature reviews reveals a mixed result composition in relation to relationship between workers' education about the brand on employees' brand citizenship behavior. According to research findings of King \& Grace (2008) brand knowledge affected the employees brand role in this regard and how they are willing to engage in brand supportive behavior. But Kimpakorn and Tocquer (2009) have failed to find much support on brand knowledge and how it influences employees brand commitment and other behavior required for brand support. Furthermore, according to assumptions of Burmann et al. (2008) brand knowledge works as a mediating variable, but not as a key determinant of employees' BCB. Evidently, employees especially in the service industry implicitly project the brand identity to consumers (Kimpakorn \& Tocquer, 2010).

\subsection{Customer perception}

The delivering of superior customer service has become vital for a company to have a sustainable relationship with their customers. The new focus on customer profitability has revealed that the effective management of satisfied and faithful customers gains the company an improvement of economic and competitive situation (Yang \& Peterson, 2004). According to Khalifa (2004), the perceived customer value definitions can be grouped into three main categories: benefits/costs ratio models (utilitarian), value components models, and means-ends models. In researching of conceptual customer perceptions of price, quality and value, Zeithaml (1998) described value as the ratio of customer perceived product utility (benefits received) divided by the price paid (the costs suffered and other sacrifice), and emphasized that customer value is based on personal perception. According to Woodruff (1997), customer value is customer's perceived preference for and evaluation of advantages of product attributes and the results of usage, which enable the customer to achieve the desired goals. Therefore, benefits/costs ratio models define value in relation to pricing as the difference between customers' perceptions of benefits received and sacrifices incurred, and include tangible and intangible attributes of the product/service (Leszinski \& Marn, 1997; Monroe, 1990; Gale, 1994; Zeithaml, 1988; Huber et al., 2001; Woodruff \& Gardial, 1996; Groth, 1994; Horovitz, 2000).

There are no clear-cut answers on how customers perceive value, why they switch the bank and what value dimensions are of key significance when making the above decisions. It can be supposed that banks inability to evaluate customers' expectations and perceived value, therefore, their offer 
sometimes is not valuable for customers. According to Khalifa (2004), the perceived customer value definitions can be grouped into three main categories: benefits/costs ratio models (utilitarian), value components models, and means-ends models. In researching of conceptual customer

perceptions of price, quality and value, Zeithaml (1998) described value as the ratio of customer perceived product utility (benefits received) divided by the price paid (the costs suffered and other sacrifice), and emphasized that customer value is based on personal perception. According to Woodruff (1997), customer value is customer's perceived preference for and evaluation of advantages of product attributes and the results of usage, which enable the customer to achieve the desired goals. Therefore, benefits/costs ratio models define value in relation to pricing as the difference between customers' perceptions of benefits received and sacrifices incurred, and include tangible and intangible attributes of the product/service (Leszinski \& Marn, 1997; Monroe, 1990; Gale, 1994; Zeithaml, 1988; Huber et al., 2001; Woodruff \& Gardial, 1996; Groth, 1994; Horovitz, 2000).

Organizations create brands to encourage positive customer associations and employees are directly engaged delivering the brand promise to customers (Punajaisri, et al, 2009). To effectively deliver are vitalized brand to employees and customers, organizations need to ensure that appropriate recruitment, training and motivation is in place (Zeithaml et al., 2006). Internal branding is vital in promoting the new brand to employees within an organization so as to establish greater congruence between internal and external brand messages (Mitchell, 2002). Internal branding requires implementation of an internal communications programme to encourage and inspire employees to support the new vision (Malmelin\&Hakala, 2009). Internal branding is about creating an emotional connection between employees and organization that transcends their personal experience, to create a brand vision in employees' mind that mobilizes support for the brand in every decision they make (Mitchell, 2002). Thus, internal branding aligns the employees' brand experience with the desired customer brand experience (Moosley, 2007). Organizations use internal branding to ensure employees are part and parcel of the rebranding process, which facilitates how successful they represent the brand's qualities to customers (Keller, 1993). The more employees are informed about brand changes, the more comfortable they are in communicating the brand values to customers. Thus, internal promotion of the brand not only allows employees to understand the brand but encourages employees to take ownership of the brand through their organizational responsibilities (Devasagayam, etal, 2010). According to Schiffenbauer (2001), without internal branding the brand message is not supported by unified employee behaviour and the message loses credibility. Organizations need to take time during the rebranding process to ensure employees internalize and commit to the new brand values (Kaikati, 2001).

Employees can make or break an organization's brand, thus overlooking internal branding can significantly reduce the potential impact of the organizations' external brand experienced by customers (Sartain, 2005). Brand performance depends on the how employees perform their roles in delivering the 
brand promise based on the brand standards (Punjaisri, et al, 2009). The stronger employees 'identification, commitment and loyalty to the brand, the more successful the rebranding strategy will bias the more probable that managers and employees will act in accordance with the corporate brand values (Harris \& de Chernatony, 2001). Gotsi and Andriopoulos (2007:351) indicate that one major pitfall of corporate rebranding, is that employees are often on the receiving end of the re-branding process as they often receive information after the strategy is initiated, which is 'a dangerous practice. It denotes that when staff is unable to substantiate the corporate brand promise in their customer encounters, it causes for negative reactions. Internal branding influences employee's brand identification, brand commitment and brand loyalty, which can determine the overall performance of the brand (Punjaisri, and Wilson, 2007).

\section{SUMMARY OF DISCUSSION}

Research studies carried out on the topic area of brand citizenship behavior has been increasing considerably when the past decade is being considered. However, less research studies are found referring impact of Customer perception in this aspect. The concept of $\mathrm{BCB}$ has been found as important matter that ensures employee commitment in different industries (Helm, et.al.2016). Researches are found reviewing the role of BCB in Sri Lankan services including NBFI sector whilst further studies are encouraged (Nirmali, et.al.2018). We highlight the intensive human resource efforts done by NBFI sector in Sri Lanka to improve knowledge and behavioral improvements of the employees. The overall purpose is to motivate $\mathrm{BCB}$ resulting higher level of customer perception and customer service commitment. Employees' loyalty to the brand is vital as it allows the organization to respond effectively to customer requirements and drives down costs through reduced recruitment and training expenses (Punjaisri, et al, 2009) In organizational perspective, companies expect to improve customer perception through focusing on training and development activities and organizational environment factors said that are being given consideration and priority (Burmann \& Zeplin, 2005). In brief, $\mathrm{BCB}$ can be described as a collection of general employee behaviors that could altogether enhance brand identity. The employees with high level of BCB essence will voluntarily offer their maximum potential towards superior customer service as well as organizational goals. Therefore, arguments are still found $\mathrm{BCB}$ connects more in to branding or employee behavior. But, branding connects employees into promised brand values, especially in services (Kahandawaarachchi, Dissanayake \& Maitra, 2016). Supportively, BCB injects self - development of staff in brand values and are able to communicate positively about the brand ( Burmann and Zeplin , 2005 ).

Thus, Gonring (2008) suggests a significant link between employee engagement and customer loyalty. Employee loyalty results in employees being brand advocates in delivering a unified customer experience and without loyalty present there is a quantifiable impact on the customers' experience, brand equity and shareholder value (Heaton \& Guzzo, 2000). As per Burmann and Zeplin (2005), there 
are seven key attributes that lead the employee behavior influencing living the brand concept, which is termed as "brand citizenship behavior (BCB). These seven key attributes include (helping behavior of employees, self-development and self-attainment of employees, enthusiasm toward the brand, and consideration of the brand, sportsmanship that is radiated, advancement of brand and endorsement of brand. Moreover, the latest studies Burman et al (2009) recommended further investigation within a quantitative data set. Therefore, a large - scale quantitative validation of the dimensions was done by Shaari et al, 2012) where they identified four dimensions of BCB: helping behavior, sportsmanship, self-brand development and brand endorsement. Therefore, the researchers have recommended that measuring activity of $\mathrm{BCB}$ should be carried out in such a way as to test to derive the advantages

\section{CONCLUSION}

This paper articulates a concept review of brand citizenship behavior and Customer perception. This study has been mainly focused on past literature-based approaches. Thereafter, the researcher has attempted to discuss the impact of brand citizenship behavior and customer perception by providing future research directions. Accordingly, this paper highlights empirical gaps of studying the impact of brand citizenship behavior towards financial services (Dissanayake \& Ismail, 2015; Nirmali, et.al.2018), whilst specific attention has been made on customer perception of non bankling financial institutions in Sri Lanka. Specifically, Organizations create brands to encourage positive customer associations and employees are directly engaged delivering the brand promise to customers (Punajaisri, et al, 2009). and this paper suggests customer perception as a key investigation area. Service sector including NBFI sector of Sri Lanka has been highlighted as a research context demands extended studies in relation to internal branding practices result service performances (Kahandawaarachchi, et.al.2016). Additionally, the concept of brand citizenship behavior is a wider subject arena and the perspective and opinion towards a brand might be different from person to person or time to time. According to Abdullah, Omar \& Rashid (2013), employee commitment on performance is attributed through personality traits of employees in banking sector firms, and further studies have been suggested. Sri Lankan sales forces are the most critical segment finds retention issues, and it may be attributed by different demographic and psychographic factors of staff besides organizational norms (Wimalana, 2017). Thus, authors suggest that brand citizenship behavior should be further studied by giving special reference to personally traits as one of the staff attributes to examine behavioral outcomes. Conclusively, paper highlights the empirical requirements referring Sri Lanka as a specific context to examine how BCB and related internal marketing tools result staff retention behaviors including brand supportive commitments. 


\section{REFERENCES}

Abdullah,I., Omar, R. \&Rashid,Y.(2013). Effect of Personality on Organizational Commitment and Employees' Performance: Empirical Evidence from Banking Sector of Pakistan, Middle-East Journal of Scientific Research 18 (6): 759-766, DOI: 10.5829/idosi.mejsr.2013.18.6.1685

Berry, L. (1981) 'Employee as customer', Journal of Retail Banking, 3,. (1): 33 - 40.

Belt, J. A .and Paolillo, J. G. P. (1982). 'The influence of corporate image and specificity of candidate qualifications on response to recruitment advertisement', Journal of Management, 8 (1): 105 - 112

Burmann, C Zeplin, S \& Riley, N 2008, 'Key determinants of internal brand management success: An exploratory empirical analysis', Brand Management, 21, (. 1): 1-19. Chimhanzi , J. ( 2004 ) ' The impact of marketing/ HR interactions in marketing strategy implementation ', European Journal of Marketing , 38 , (1/2 ) : 73 - 98 .

Chimhanzi, J. and Morgan, R. E. (2005). 'Explanations from the marketing/human resources dyad for marketing strategy implementation effectiveness in service firms', Journal of Business Research, 58 (6 ): 787 - 796.

Central Bank Report (2017). Central Bank of Sri Lanka

Dissanayake, D.M.R. (2015). Factors Determine the Customer-Celebrity Relationship towards Perceived Celebrity Endorsements: Propositions to Hypothesize Future Studies in Sri Lankan Services Sector, Sri Lanka Journal of Marketing (SLJM), 1, (2): 1-19.

Dissanayake, D.M.R. \& Ismail. ( 2015). Relationship between Celebrity Endorsement and Brand Attitude: With Reference to Financial Services Sector Brands in Sri Lanka, Conference Proceedings, International Conference on Business \& Information (ICBI), 1,(2):1-22.

Feldwick, P. ( 1991 ) 'Defining a brand' , in Cowley, ‘ Understanding Brands ',KoganPage,London , 21 .( 39 ) Ind , N . (2004) 'Living the Brand: How to Transform Every Member of Your Organization into a Brand Champion', 2nd edn, Kogan Page, London.

Floyd, FJ \&Widaman, KF 1995, 'Factor analysis in the development and refinement clinical assessment instruments', Psychological Assessment, 7 (1): 286- 299.

Glassman, M. and McAfee, B. ( 1992 ) 'Integrating the personnel and marketing functions ', Business Horizons 35 ( $3) .52-60$

Hatch, M . J .and Schultz, M. ( 1997 ) 'Relations between organizational culture, identity and image ' European Journal of Marketing , 31 , ( 7/8 ): 356 - 365 .

Hankinson, P. , Lomax, W. and Hand, C. ( 2007 ) ' The time factor in re-branding organizations: Its effects on staff knowledge, attitudes and behaviour in UK charities ', Journal of Product \& Brand Management, 1 ( 2) : 10 -15

Hasnizam Shaari, Salniza Md. Salleh,\& Zolkafli Hussin (2011).“Exploring the Dimension of Internal Brand Citizenship Behaviour in Malaysia:A Case of Northern Malaysia: Hotel World Review of Business Research. 1. ( 1) March 2011..

Kahandawaarachchi,L.K.K., Dissanayake, D.M.R. \& Maitra ( 2016). Role of Relative-Agency of Consumers in Brand Building: Conceptual Review for Marketing Implications and Future Studies, Sri Lanka Journal of Marketing, 2,( 2): $31-53$. 
Helm, S. V., Renk, U., \& Mishra, A. (2016). Exploring the impact of employees' self-concept, brand identification and brand pride on brand citizenship behaviors. European Journal of Marketing, 50(1/2), 58-77.

Keller, KL 1993, 'Conceptualizing, measuring, and managing customer-based brandequity', Journal of Marketing,. 57 ( 9$)$ : 1-22.

Kimpakorn, N \&Tocquer, G 2009, 'Employees' commitment to brands in the service sector: Luxury hotel chains in Thailand', Journal of Brand Management, . 16 ( 1 ) 532-544.

King, C \& Grace, D 2008, 'Internal branding: exploring the employee's perspective; Journal of Brand Management, 15 (1): $358-372$

King, C \& Grace, D 2010, 'Building and measuring employee-based brand equity', European Journal of Marketing, 44 (7-8): 938-971.

Lings, I., \&Greenly, G., 2005. Measuring Internal Market Orientation. Journal of Service Research 7 (3) :290 - 305.

Maitra, R. \& Dissanayake, D.M.R. (2015). Employer Branding Practices: Case Review on IT Sector Companies in India, Scientific Research Journal (SCIRJ), 3,(8) 2201-2796, 21-26

Morhart, FM, Herzog, W \&Tomczak, T 2008, 'Brand-specific leadership: Turning, employees into brand champions', Journal of Marketing, 73 ( 2): 122-142.

May, D. R., Gilson, R. L and Harter, L. M. ( 2004 ) ' Psychological conditions of meaningfulness, safety and availability and the engagement of the human spirit at work', Journal of Occupational \& Organizational Psychology, 77 (1): $11-37$

Nirmali,A.K.A., Ali Khathibi,A. \& Ferdous Azam,S.M. (2018). Exploring Employees Brand Knowledge in Sri Lankan Banking Sector, European Journal of Social Sciences Studies, 3.(, 1) :14-23,DOI: 10.5281/zenodo.1283767

Rousseau, D. M. ( 1990 ) 'New hire perceptions of their own and their employer's obligations: A study of psychological contracts ', Journal of Organizational Behaviour, 11 ( 5 ): 389-400 .

Robinson, S. L. and Morrison, E. (1995). 'Psychological contracts and organizational citizenship behaviour: The effect of UN fulfilled obligations on civic virtue behaviour', Journal of Organizational Behaviour, 16 (1):. 289 - 298.

Robinson, S. L .and Rousseau, D. M. (1994). 'Violating the psychological contract: Not the exception but the norm', Journal of Organizational Behavior, Vol. 15, pp. 245 - 259. (43) Johns, N. (1999) 'What is this thing called service? 'European Journal of Marketing, 33( 9/10: 958 - 973

Spence, M. (1974). 'Market Signaling: Informational Transfer in Hiring and Related Screening Processes', Harvard University Press, and Boston, MA.

Verma, T., \& Dhar, S. (2015). Dimensions of brand citizenship behavior in Indian context: An empirical analysis. JIM QUEST, 11(2), 68-76.

Wilden, R., Gudergan, and S. And Lings, I. (2006). 'Employee-based brand equity', in Drennan, J. (ed.) 'Proceedings of ANZMAC', QUT, Brisbane.

Wimalana, N. (2017). The Determinants of Sales Force Turnover in FMCG Industry - An Empirical Study in Sri Lankan Context, The International Journal of Business \& Management, Vol 5, 12, 277-286 